\title{
IT TAKES MORE THAN ETHICS
}

\author{
Chris R. Simpson \\ Co-director of the Australian Institute of Computer Ethics (AICE) \\ Lecturer at the School of IT, Swinburne University of Technology (SUT). \\ Email: csimpson@swin.edu.au
}

\begin{abstract}
Recent positive developments in ethical outlook are explored, initially within the Information and Communication Technology (ICT) profession, and then broadened into other disciplines and the community in general. To understand why there has been a growing ethical problem in the first place, ethical attitudes of university students, ICT exponents and people in other disciplines have been observed and noted.

The search for practical ethical guidelines continues by questioning why, if professionalism indicates an adherence to a code of ethics that seeks high standards, do we still have trouble with the concept of ethics? Ethics differ from one group to another. Furthermore, ethics keep changing, as is evident in the latest codes, in which 'public good' now comes before the more inward-looking 'good of the profession'.

So, how could an ethical code be more than an isolated, somewhat ineffective and temporary set of guidelines? How can it be freed of boundaries, of context and of time? How effective or relevant is the education of university students in practical ethics? How effective are the professional and ethical bodies?

Some answers are proposed and along the way, together with some simple but powerful notions and tools, that facilitate ethical understanding in university education and in professional practice.

It is then argued that as work is a part of life, then a similar range of ethical options would be available in every context of life, be it as a private individual, a society, an employee, a small business, a corporation or in whatever discipline or role. In each situation, a similar range of lifestyle choices exist, for example, wasteful (careless), indulgent (selfish), sustainable (prudent), long-term view (responsible) or a perpetual view (meaningful and truly progressive).

In other words, by agreeing to adopt 'the community ethics', one has taken on a dutiful role. For it to be more meaningful and more fruitful, life further demands such things as care of others and environment, along with some sense of humility, giving, gratitude, purpose, distant vision and wardenship.

How can ethical guidelines transcend into being 'inspirational' guidelines, independent of occupation? Is this not the realm of higher values? And if so, is this essential to the fundamental progress of human-kind?

It may well be so. A few more simple observations and tools are offered that could be of assistance.
\end{abstract}

\section{Keywords}

Business, Change, Codes, Computer, Communications, Community, Consequences, Education, Ethics, Grassroots, ICT, Information, IT, IS, Practical, Professional, Responsibility, Technology, Tool, University, Values.

\section{INTRODUCTION}

This relatively short essay reports my views of the progress of ethical considerations in the field of Information and Communication Technology (ICT), and more broadly, in recent times in Australia. At present, ICT is not yet overtly values-driven: not in its design phases, nor its implementation, nor its application nor its use. I would dearly like to think that it could be. Optimism or idealism aside, let us examine what would need to happen in order to say otherwise. Time will tell, of course, but the good news is that mounting activity is occurring that is worthy of note. Indeed, much has happened in the last few years that renders the prospect of utopia ever closer. Let us trace some aspects of recent changes in ICT outlook, then explore various prevailing external influences and finally propose broad and useful strategies that may encourage positive progress in the future, not only in ICT, but in every avenue of life.

\section{ICT Education}

Where does an appreciation of moral behaviour begin? At home? In school? At Church? At Scouts or Guides or other service organisations? Certainly before the 1970's it did. Now, however, these institutions have either almost disappeared from public interest or waned significantly in influence as far as overt morals education goes. Even at home, parental influence has on average diminished, as both (or a single parent) are commonly working full-time or are disinterested in morals or both. Morals training was stripped out of school curricula in the mid 1970's. I have written extensively about this in my paper given at ETHICOMP99 [Simpson, 1999]. Many students have been coming to their final year of university having seldom if ever formally thought about ethical issues relating to computing or, in more cases than expected, relating to any facet of life. Only in the last two or three years has there been any hint of a return to certain schools of some formal morals coaching, and a few of these students are approaching final year university now in 2000 .

A big difference, noticeable over the last five or so years, has been the initial declared outlook of students as they enter my final-year computer ethics subject. Let me explain that the subject, once called Computing in the Human Context and now renamed Professional Issues in IT (PIIT), is compulsory in all undergraduate degree courses in the School of IT at Swinburne University of Technology. Whereas five years ago a significant number of students were cynical, and some remained so for the whole semester, now there is a much more 
willing and accepting outlook, along with a realization that such studies are important for their professional careers ahead. Moreover, quite early in the semester, some are questioning why such a subject is not part of courses run by other departments of the university.

The PIIT subject stands alone in our IT/IS courses [Simpson, 1998]. It has changed, developed and matured since 1990. While still serving to fulfill the accreditation requirements of the Australian Computer Society (ACS), it also attempts to redress the gross imbalance between technical and non-technical course-work that is completely out of step with the actual demands of professional practice. Most significantly, it now serves well as a last-minute band-aid attempt to bridge the ethics gap. The gap is so wide that it is necessary to include in the syllabus countless opportunities and strategies to promote deep reflection and self-evaluation - and to write about them. Several aspects are introduced such as "What has ethics to do with me?"; generational differences; cultural differences; working in a team; ethical issues in Artificial Intelligence, in computer crime, in IT law, and in globalisation; professional associations and codes; and responsibility.

Recent years have seen ethics-oriented subjects appear in IT or IS curricula at other universities. For example, in the School of Computing and Mathematics at Deakin University, which has a long history in distance education, there exists an equivalent subject. It is called Computers and Society and Professional Ethics and is run by Dr. Jo Coldwell [Coldwell, 2000]. It uses a completely different approach, being largely web-based and organised as an on-line "conference". Small group work is possible in asynchronous "sub-conferences", in which the results of group discussions upon each topic are posted on plenary pages. Both this approach and that of Swinburne's PIIT subject are highly dependent upon students' personal involvement and introspection.

These two approaches involving personal development and practical ethics are in stark contrast with various other implementations of an equivalent subject, in which for example, a bit of applied ethics (Aristotle \& co) plus some law cases plus some basic sociology or psychology theory may be included. I feel that this more theoretical approach would constitute a reasonable second rung should it exist in a subject stream, but that students are simply not ready for it without a solid notion of practical ethics, that is, who they are, what they believe, how they fit into the world and how they can take on moral responsibility.

\section{ICT Professionalism and Practice}

Although some would criticize by asserting that IT professional bodies still have "no teeth" and that few practising ICT (or IT or IS) people display committed adherence to a society or its code of ethics and practice, the ICT profession, worldwide, has taken quite a few positive steps in recent years.

Several ICT or Software Engineering codes of ethics and practice have been developed or are now updated to include a refreshing outward-looking attitude that no longer places as first priority the interests of the profession, but instead, the greater good. For example the ACS code includes first under "Values and ideals", in section 4.3.1:

"Priorities: I must place the interests of the community above those of personal or sectional interests. [ACS, 2000.a].

An excellent new Software Engineering Code was adopted jointly by IEEE-Computer Society and the Association for Computing Machinery (ACM) late in 1999 [IEEE-CS, 1999]. This code also re-prioritises first place to "the public interest" and embodies some extraordinarily released statements.

Relevant professional bodies around the world have continued to improve their position. For example, in Australia, ACS demands a certain level of competency in ethical studies for university courses to be accredited, and have developed a requisite "body of knowledge" and a Professional Recognition Program, which is "supported by the increasing number of organisations declaring a preference for ACS" [ACS, 2000.b]. Since January 1999, ACS embraces a Computer Ethics Taskforce (within the ACS Community Affairs Board's Economic, Legal and Social Implications Committee) [ACS, 2000.c].

Yet the criticism of "no teeth" is not yet overcome. How can ICT be recognized in the same light as (say) the medical profession, when the bulk of ICT exponents do not have an accredited qualification, and of those that do, only a modest percentage in Australia have been members of the ACS, and of those, only those who joined in the last few years will have taken requisite ethical studies. There is no National Register of Computer Consultants. There is no Hippocratic Oath or its modern-day equivalent, nor a significant track record of successful tribunal challenges for malpractice, nor the overwhelming cooperation of the discipline's following. Education at all levels is a major key to the problems just stated. Education and advice is precisely what some ethical organisations (such as AICE), which are external to the professional bodies, wish to offer in support of existing internal programmes for computer professionals. In addition, external organizations can offer public education and advice aimed at stimulating all sectors of the community to recognize and acknowledge ethical professional behaviour. 


\section{ICT Practice - New Tools}

For some time, the practice of ICT has been aided by software tools, project management tools and business packages. Not until very recently have there emerged tools that go beyond purely technical design considerations; tools that begin to consider value statements and flow-on effects beyond the client and into the community and environment, and that pay attention to "distant vision": all of these being hallmarks of excellent and ethical design.

One notable example assists with a style of risk evaluation that goes beyond technical issues into overtly ethical regions. The notion of preparing a Software Development Impact Statement that looks into the consequences of a project beyond client organization economics is quite new. A package called SoDIS [Gotterbarn, 1999] is currently in its final test phase, although it will most likely be revised as more experience is accumulated. Its operation is explained in Don Gotterbarn's paper [ibid]. Basically, it takes the project task list and asks thirtytwo ethical impact questions about every task in turn of each of the relevant stakeholders in the project, both close and distant, in turn, whether there are ethical consequences of that task for that stakeholder (yes or no). A map of responses is generated and an ethical risk profile may be generated. Establishing a complete list of stakeholders is crucial to the success of this method, as some stakeholders are anything but obvious initially.

Another instance of a software engineering tool with built-in ethical considerations has been proposed in a recent paper by Rogerson, Weckert and Simpson. The structured systems analysis and design method (SSDAM) is an established design methodology. It is a "hard" systems approach, which is shown can be enriched by incorporating various principles from a code of ethics, in this case the ACS code of ethics [Rogerson, 2000].

\section{ICT Ethics bodies}

Over the past few years, parallel to the rapidly increasing public use of the word "ethics", interest in computer ethics has also risen quickly in the community, particularly within academic circles. Ethics bodies have been formed that have high ideals and aim to promote them. The Australian Institute of Computer Ethics (AICE) is but one that runs seminars and international conferences and ties into academic programmes. There are many other Australian bodies such as Internet Industry Association (IIA) and Electronic Frontiers Association (EFA) that have sectional interests within the overall technology, and who are all contributing strongly to a new level of public grasp of ethical issues. It is much the same globally.

AICE has a distributed presence in several locations around Australia. It operates differently in each of its Chapters and accumulates valuable experience and resources along the way to redistribute as the opportunities arise. It is alive by virtue of the energies of its members (or more correctly, "Friends") and its network of collaborating and supporting bodies. Strong and productive links exist between AICE and similar bodies all over the world, such as CCSR in UK, RCCS and SEERI in USA and FICT in The Netherlands, as well as connections with individual gurus and friends in the field. The network is even stronger considering the personal links of our members, particularly through AICE's other Co-director John Weckert.

\section{Beyond the ICT Fraternity}

It is pointless to limit our attention exclusively to exponents of ICT. Most computer ethics issues extend to users in all disciplines, occupations (work) and in fact, every aspect of life. Work is a part of life, so what is good for life should be good for work, although thousands might initially disagree. In support of this assertion, we should enquire: who else has recently taken up the cause of "ethics"?

\section{Other Professions and the Business world}

The older professions have rigorous sets of controls that have used peer pressure to good effect. The entry conditions are extremely tight; the oath and/or code are binding; a practising register is maintained; fellowship is highly sought after; any minor blot on one's ethics of practice is remembered for ever. Why then is the community at odds with certain decisions of such professional bodies over some recent ethical issues? Perhaps there are shortcomings in the code relating to protection, or maybe there are unknown processes behind the scenes? I am merely pointing out that community ethics are continually modifying, and that even the most respected professions need to be conscious of these changes, particularly the currently perceived need for transparency of process and "public interest". Many citizens are losing respect for outdated, expensive and unfair practices. I believe that the budding new ICT profession is now and will try very hard in the future to maintain a close watch on the public interface and ethical aspects of its operations. Success will depend upon its members and their perception of "ethics".

The world of business is undergoing huge change. That is good news, because the recent trend has been towards annihilation of the world's resources and dehumanisation of its people! 
Many would assert that 'Business is unprincipled'. But what are we talking about here? Managers, Economists, Accountants? No, I do not think so. Has not the same prevailing narrow set of values been enforced upon all professionals and, in fact, anyone in almost any organisation? A notable factor is that the stakes are higher as the promotion ladder is ascended. Like ICT, "Business" pervades most of the community. Unfortunately, the limited set of values, summed up by "the bottom line", goes with it and affects us all.

Another external force that has considerably tightened its business-oriented grip in the last few years is that loosely called "Globalisation". Originally the thought of 'hands across the seas' was most attractive to generoushearted people, who cared about (say) third world inequities. However, it was seized upon by trans-national "Gnomes" as an excuse to become two faced - providing work in underdeveloped countries, but in reality exploiting them pitifully and worsening the inequity. Able to thumb their noses at national governments, they have further disdained border controls and taxation responsibilities by applying recent developments of internet technology and exploiting its relative global freedom as well.

What then is the change? Is it all for the worse? On the contrary, in the last two or three years, there have begun to emerge practical expressions of what has been yearned for by many and talked about for the past decade by bodies like the St James Ethics Centre (see below). The concept of a "triple bottom line" is now being taken up by some corporations both in Australia and around the globe. This term infers a value system that broadens the old and lonely economic values by adding human (social) values on one side and environmental (sustainability) values on the other. The net effect is that better decisions can be made with this system. It also has the effect of reducing overt greed, which, I believe, has ultimately caused the rampage alluded to above.

How has this positive change come into being? Grass-roots action by ethical bodies has set out to convince "Business" that in every sense there are better results available by adopting broader values for decision-making. Instrumental ethical bodies were not confined to the ICT group! Of course there have been other bodies, together with outspoken individuals, not to mention the prophets of a decade or two ago.

\section{Other Ethics Bodies}

Within the last five years particularly, many ethics groups with broader or overlapping spheres of interest have been created. I shall mention but a few that have immediate proximity.

Through John Weckert, who leads the Charles Sturt University (CSU) chapter of AICE, intimate ties exist with the Australian Association for Professional and Applied Ethics (AAPAE). This is a formal, academic association based at CSU that has recently won collaborative grants to support high levels of research activity.

The Business Ethics Research Unit (BERU) is based at Victoria University and runs frequent seminars, concentrating upon ethics in the business context. BERU has existed for about two years, is already productive in research and has member-level links with AICE.

The Ethical Enterprise Network (EEN) aims to "help our members adopt ethical practices within their own enterprises; and build awareness in the community about ethical, sustainable and just business practices." EEN also aims to build networks between ethical enterprises through membership, a regular newsletter, meetings and sharing of information about ethical activities, internal and external. [EEN, 2000]

The St James Ethics Centre is based in Sydney and has successfully run for more than 10 years, having attracted excellent patronage and an effective team of consultants. It has a very broad sphere of interest and has solid connections with the business world. AICE has personal links with a Melbourne project office that was opened in February 2000.

A cooperative organization with whom AICE has a personal link is "Borderlands", founded in 1997, which "is a place where people can meet, talk, reflect, learn and teach, read and study, organise, administer and manage their networks or activities in and from. [A place] where consultation, consulting and counselling can happen, where a broad spectrum of basic resources are made available and accessible and which thus would become a node of various intersecting local, national and international networks." [Borderlands, 2000]. It aims to involve citizens and groups at a grass-roots level of ethical and ecological concern.

\section{When do "ethics" cease to be useful?}

A number of positive and most releasing ideas are embodied in the terms "best practice", "greater good", "public good", "public interest" and "ethics". However, all of them have become embarrassing through the number of interpretations being made of them. There are almost as many definitions of these phrases as there are sectional interests! Let us examine "ethics" in particular.

Ethics, as suggested already, is a problematic notion: ill-defined and either good or bad. Specifically, ethics differ between different social groups and cultures and are subject to change. They are expressions of group norms, being the expectations of behaviour in that group, whether aspirational or destructive, often ending up as the lowest common denominator! "Good ethics" need to be defined too. A number of definitions may be found in the various professional and corporate codes of ethics and practice, which frequently go only so 
far towards providing behavioural guidelines, as they are intended for use within a defined context. The best codes therefore look outwards. They define and prioritise "greater public good" before all else. Likewise, the tenets are broad in nature.

However, even this marvellous breakthrough of outward-looking codes is not ultimately sufficient. Why? Because no code, to my knowledge, can adequately cope with boundaries that exist between national, cultural or sectional interests, especially when put to the acid test. Furthermore, what is the greater public good?

\section{Are there alternatives?}

Yes, there are alternatives, because life is greater than this. True and effective human communication transcends boundaries of all kinds, be they professional, sectional, cultural or national. Every professional person, or any person per se, therefore needs much broader and more universal guidelines than just those internal to a profession or group. What might these be? Maybe the highest shared values - those that are common to all mankind thereby transcending all boundaries. If so, what are they?

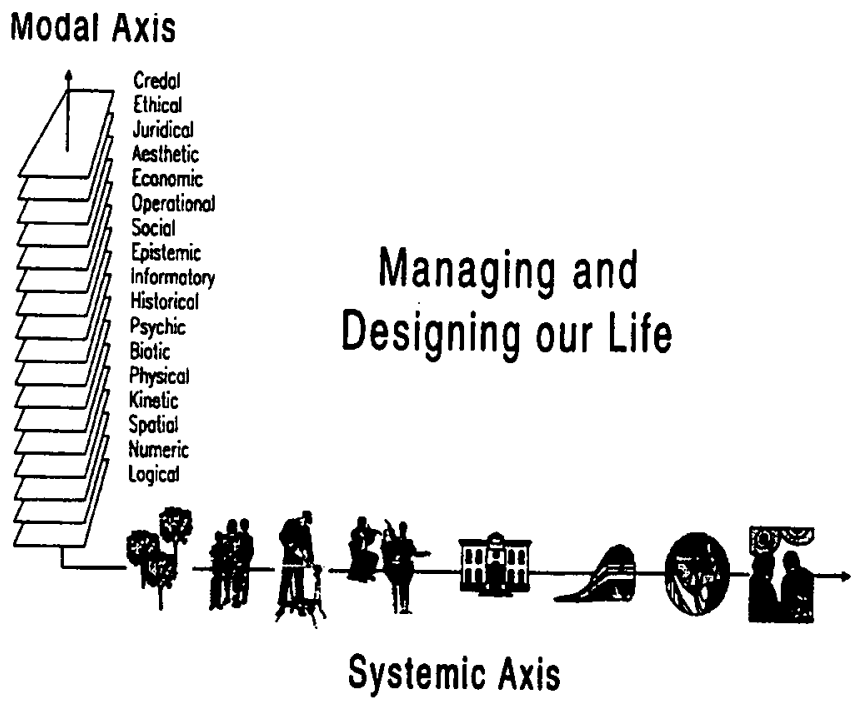

Figure 1: Multi-Modal Systems Framework

\section{Some tools for viewing higher values}

Rushworth Kidder wrote a charming book, entitled "Shared Values for a Troubled World" [Kidder, 1994]. In it, he sets out his plan in the first chapter and then reports captivating conversations with twenty-four people, each well respected and each of widely differing race, creed, context and circumstance. His aim was to establish what values each of these people felt were the most important to them. Kidder then ranked the most common of the values. There emerged eight shared values common to all:

love, truthfulness, fairness, freedom, unity, tolerance, responsibility, respect for life. All of these pass the test for being "on the highest rung of the visionary ladder" [ibid p323]. That is, if one asks why, for example "why does truthfulness matter?" there is simply no sensible, worldly answer. He sums up the book with: [ibid p324]

"So what good is this code of values? It gives us the way to build downward to the level of goals, plans, and tactics, where things really happen and the world really changes. It unifies us as we move around on the ladder, giving us a home territory of consensus and agreement. And it gives us a way - not the way, but a way - to reply when we're asked, "Whose values will you teach?" Answering this last question as we tumble into the twenty-first century with the twentieth century's sense of ethics, may be one of the most valuable mental activities of our time."

Being universal and perpetual, these higher values of mankind can be adopted personally just as easily as by a group or profession. Further, being absolute, they are paradoxically impossible to categorise, as they know no boundaries.

Donald de Raadt writes about an interesting way to analyse one's activities [De Raadt, 1997]. The "Multi-Modal Systems Framework" is a social analysis tool that looks at everyday activities via a wide range of modes, thus assisting the clarity of one's thought processes.

The model uses modes that range from: 
Logical, Numeric, Spatial,... ...to... ...Economic, Aesthetic, Juridical, Ethical, \& Credal. （See Figure.1)

To view any social instance is made much simpler by viewing each mode separately, by using its appropriate telescope that filters out all but one mode of behaviour. This exciting model acknowledges the higher values in the so-called credal plane, in which activities are pursued out of faith, rather than out of duty as in the ethical plane. The model continues to be developed at the Centre for Technology and Social Systems (CTS) a joint Swedish and Dutch collegium, sometimes called 'Swehol'.

\section{Responsibility measurement}

A call for papers for the International Society for the Systems Sciences, 42nd Annual Meeting, Atlanta Georgia, USA, 19-24 July 1998 stated: "A distinguishing feature of today's world is that technology has built the house in which we all live. More and more, our lives are lived within the confines of its walls. Yet this implies that technology entails far more than the material artifacts surrounding us. Technology has in fact become a very complex system that confronts us with new dimensions of human responsibility".

I show my students a way to measure responsibility, certainly a useful tool for a professional person. We talk about responsibility relating to context, commitment, the bearing of consequences and values. This leads us to propose that the level of responsibility could be measured in four ways:

Commitment (intended duration/nature of responsibility);

Moral motive behind taking on the responsibility;

Context within which the responsibility is carried out and;

Scope of (project) consequences.

These could be represented, visually graded, on a composite table of four independent columns:

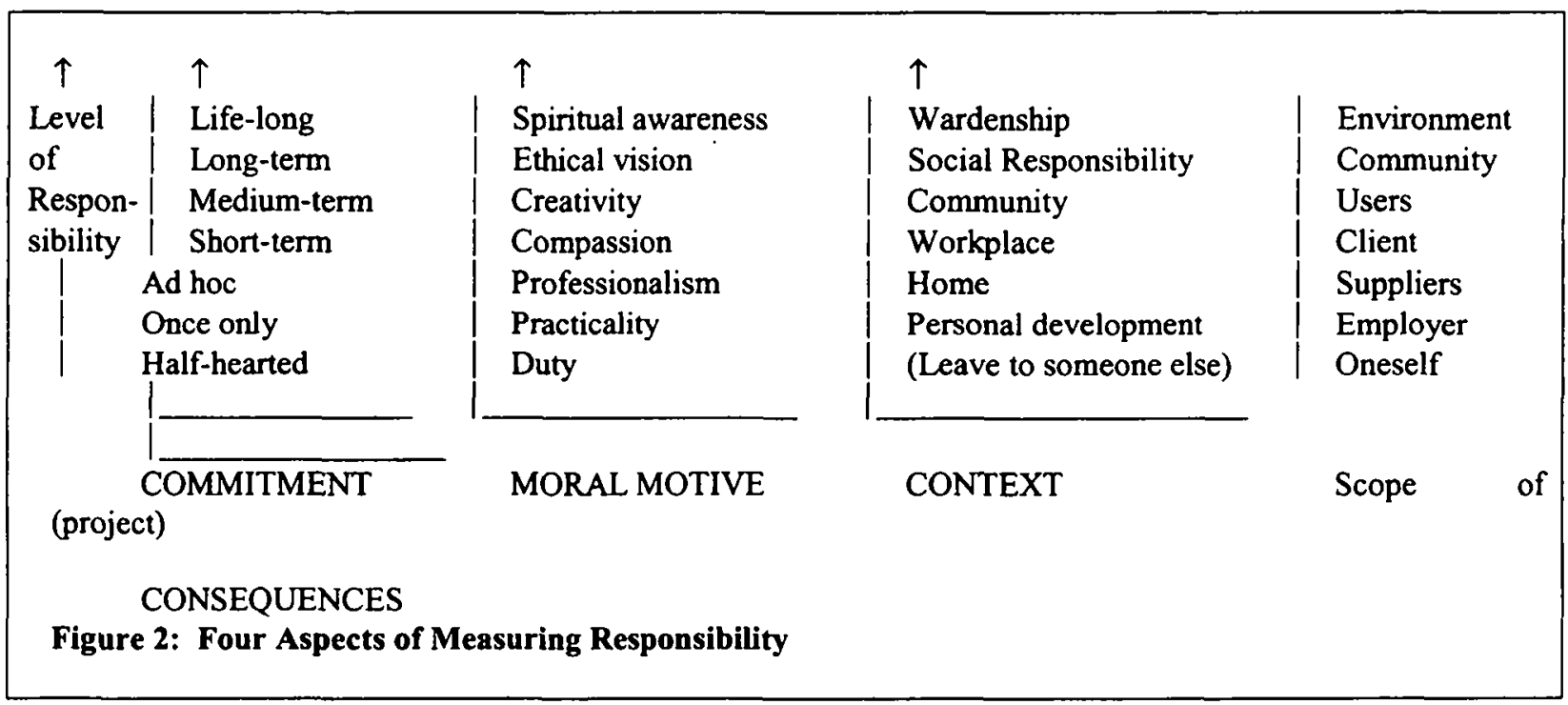

The imperfect but useful graphical ideas given here in figure 2 reflect both Kidder's results and the Multi-modal model shown in figure 1 .

I go on to suggest to my students that responsibility is an attitude, a moral commitment to a way of life. Bearing in mind that nothing tangible will be achieved until one actually does something. It is no good to sit on one's bottom, glowing with "responsibility". One needs to be proactive and actually take responsibility that a certain something happens. But then there is a process. First, one needs to perceive the problem. The need is usually thrust upon us by circumstance. Once recognised, it means that one is ready to take on the task, as one's experience, maturity and sensitivity has rendered it visible. Next comes the decision whether to make a commitment, and this is often the most difficult step to take. Once the decision is made, one may identify where one lies in each of the four columns of the table in figure 2. Appropriate action is usually clear, but will often require great courage to implement, because of implied consequences. Some consequences are predictable, some unexpected and others may never eventuate. Although one must be brave and firm in the faith that one's decision is the right one, if in retrospect it turns out that it was not the right decision, one should be prepared to make good. 


\section{CONCLUSION}

Discussion so far has noted the recent general upsurge in ethical awareness, which is indeed most welcome and necessary. It reflects the excellent work that is being done to facilitate a broader understanding of what is good. Many ethically concerned bodies have evolved that can assist organizations and corporations with, for example, the creation of codes of ethics suitable for their various contexts. But it has also been argued that guidelines of a more universal nature are required, that will transcend the limitations of ethics per se, being naturally sectional and ever-changing. The shared higher values of mankind need to be identified and not only wound into corporate codes and guidelines, but also absorbed into the very being of every individual, particularly those who must assume responsibility, such as professional people. Some simple tools have been noted already that assist in understanding the existence and practicality of these higher values by placing them in graphs and priority lists of simple tools.

Idealism is a wonderful motivator, but to put ideals into practice clearly requires awareness, positive attitude, practical tools, skill to use them and both willingness and courage to match the task by taking on requisite responsibility. But the ultimate question is still unanswered: how?

In the mist of today's confusing, chaotic world of competing interests and thundering "white noise", it is easy to be distracted from higher ideals. But a cogent argument could be made here:

- That corporations and associations are just groups of individuals;

- That the ultimate decisions are those of individuals;

- That whatever guidelines an individual adopts is ultimately an individual choice;

- That this choice bears upon his or her whole life, and upon the lives of all around about, and upon the environment itself.

Therefore vital corporate or public (or any) decisions become issues of personal attitude that include responsibility and caring for others, the humility to recognize one's limitations and the passionate will to broaden one's strengths and "positive ethical conduct" [Dalai, 1999]. But as we have already asked, how do we obtain these qualities and insights? How might the "greater good" be recognized?

Perhaps there really is an urgent need in the community for:

Quietness; Contemplation;

Questioning competition and growth; Waiting patiently but proactively; Listening;

Consideration of others; Embracing wisdom; and Faith.

Such tools as these for developing one's personal higher-value skills have been around for millennia and do not need explanation here. They have become progressively suppressed and denigrated at least since the industrial revolution, and suffered especially during the past two decades in the shadow of recent "business best practices". Their reintroduction and general acceptance is long overdue.

Yet, the good news is that all this is beginning to change. And clearly, it is taking more than ethics!

As a footnote, it is comforting to note that the Dalai Lama appears to have similar thoughts. His messages of "happiness" and "positive ethical conduct" are prominent in his recent book [Dalai 1999].

\section{REFERENCES:}

Australian Computer Society (2000.a) ACS Code of Ethics, Ref. via

http://www.acs.org.au/national/pospaper/acs131.htm [accessed 15/9/00].

Australian Computer Society (2000.b) ACS Professional Recognition Program, Ref. via

http://www.acs.org.au/national/profrecog.htm [accessed 15/9/00].

Australian Computer Society (2000.c) Australian Computer Society (ACS), Community Affairs Board (CAB), Economic, Legal and Social Implications Committee (ELSIC), Computer Ethics Taskforce (CET), Ref. via http://www.acs.org.au/boards/cab/elsictr.html\#et [accessed 15/9/00].

Borderlands Home page http://www.borderlands.org.au/ [accessed 15/9/00].

Coldwell, Jo (2000) Subject: SCC383 - Computers and Society and Professional Ethics - Deakin University

School of Computing and Mathematics, Ref. via http://www3.cm.deakin.edu.au/ jojo/ [accessed 15/9/00].

Dalai Lama (1999) Ethics in the New Millenium, Riverhead Books August.

De Raadt, J Donald R (1997) A Sketch for Humane Operational Research in a Technological Society; Systems

Practice, August 1997, Vol.10, No.4, Pages 421-442.

EEN (Ethical Enterprise Network)(2000) Home page http://home.vicnet.net.au/ eenet/ [accessed 15/9/00].

Gotterbarn, Donald (1999) Promoting Ethical Responsibility in Software Development with a Software

Development Impact Statement, Proceedings of AICEC99, Melbourne, July;

(also downloadable via http://www.aice.swin.edu.au/events/AICEC99/webabstractsindex.html [accessed 15/9/00]).

IEEE-CS (Computer Society of IEEE)(1999) IEEE-CS / ACM Software Engineering Code of Ethics (Vers 5.2):

Ref. downloadable via http://www.computer.org/tab/swecc/code.htm [accessed 15/9/00]. 
Kidder, Rushworth M (1994) Shared Values for a Troubled World, Jossey-Bass, San Francisco.

Rogerson, S, Weckert, J, Simpson, C (2000) An Ethical Review of Information Systems Development - The Australian Computer Society's code of ethics and SSADM; Information, People and Technology Vol.13 No.2.

Simpson, C and Burmeister, O (1998) New Professionals, New Measures of Worth, New Ethic of Collaboration, Proceedings of ETHICOMP98 Erasmus University, Rotterdam, March.

Simpson C.R. (1999) Could Computer Ethics Spark a New Moral Generation? -An Australian Perspective, Proceedings of ETHICOMP99, Rome, November. 